\title{
Involvement of Patient Organisations in Research and Development of Orphan Drugs for Rare Diseases in Europe
}

\author{
M. Mavris Y. Le Cam \\ EURORDIS - European Organisation for Rare Diseases, Paris, France
}

\section{Key Words}

Patient's organisations - Rare diseases - Research

\begin{abstract}
Patients' representatives have an increasingly present voice in all aspects of drug development from fundamental research through regulatory processes to health technology assessment. Although major advances have been made in raising awareness and increasing funding for rare diseases, important challenges remain in terms of best use of resources, coordinating efforts and improving policy. This article describes actions taken by rare disease patients' organisations as well as initiatives at the national and European levels to promote research into rare diseases. A survey conducted by EURORDIS (European Organisation for Rare Diseases) on the support (financial and non-financial) provided by patients' organisations in rare disease research is described as well as the involvement of patients' representatives in regulatory processes for medicinal products at the European Medicines Agency. The importance of including patients' groups in fundamental and clinical research as equal partners has become a fact that clearly contributes to the success of an application and the research conducted.
\end{abstract}

Copyright $\odot 2012$ S. Karger AG, Basel (c) 2012 S. Karger AG, Basel

$1661-8769 / 12 / 0035-0237 \$ 38.00 / 0$

Fax +41 613061234

E-Mail karger@karger.ch

www.karger.com
Accessible online at:

www.karger.com/msy
There is a growing awareness of the involvement of patients in research as evidenced by several recent publications [Kaye et al., 2012; Polich, 2012] (table 1, Nr. 1; for all numbered website references (Nr.), see table 1) This is of course welcome news, but it is an awareness that many patients and patients' organisations have been struggling to increase for decades. In particular, the greatest barrier to the prevention, diagnosis and treatment of rare diseases has been and still is insufficient knowledge of the mechanisms and the natural history of the various diseases. In addition, there is little likelihood that a treatment exists for a particular disease and similarly little chance that it is being researched anywhere. The key to developing knowledge is supporting and encouraging all elements of rare disease research, including public funding for fundamental and clinical research and encouraging private sponsors to develop products for a small market.

EURORDIS (Nr. 2), the European Organisation for Rare Diseases, was founded in 1997 and is a non-governmental patient-driven alliance of patients' organisations and individuals active in the field of rare diseases. The mission of EURORDIS is to improve the quality of life of people living with rare diseases in Europe through advocacy at the European level, support for research and drug development, networking with patients' groups, raising awareness and other actions designed to fight against the impact of rare diseases on the lives of patients and their families. 
Table 1. Website references

1 http://www.rarediseasematters.org/2012/04/patient-initiated-research-foundations-a-source-of-funding-but-more-importantlya-continuous-source-of-inspiration/?goback=.gde_2422534_member_106111594

2 http://www.eurordis.org

3 http://eur-lex.europa.eu/LexUriServ/LexUriServ.do?uri=CELEX:32000R0141:EN:HTML

4 http://eur-lex.europa.eu/LexUriServ/LexUriServ.do?uri=OJ:L2006:378:0001:0019:EN:PDF

5 http://ec.europa.eu/health/files/eudralex/vol-1/reg_2007_1394/reg_2007_1394_en.pdf

6 http://eur-lex.europa.eu/LexUriServ/LexUriServ.do?uri=COM:2008:0679:FIN:EN:PDF

7 http://eur-lex.europa.eu/LexUriServ/LexUriServ.do?uri=OJ:C:2009:151:0007:0010:EN:PDF

8 http://www.eucerd.eu/

9 http://www.ema.europa.eu

10 http://ec.europa.eu/research/health/medical-research/rare-diseases/irdirc_en.html

11 http://europa.eu/legislation_summaries/energy/european_energy_policy/i23022_en.htm

$12 \mathrm{http} / / /$ www.eurordis.org/publication/patients\%E2\%80\%99-priorities-and-needs-rare-disease-research

13 http://ec.europa.eu/research/horizon2020

14 http://www.europlanproject.eu

$15 \mathrm{http} / / /$ www.eurordis.org/content/survey-patient-groups-research

16 http://www.eurordis.org/sites/default/files/publications/3_FBignami_RDD2010.pdf

17 http://www.afm-telethon.fr/

18 http://www.genethon.fr/en/

19 http://www.telethon.it/chi-siamo

20 http://www.lysogene.com/

21 http://www.alkaptonuria.info/

22 http://www.ecrin.org

23 http://www.e-rare.eu

24 http://www.e-rare.eu/content/survey-research-programmes-rare-diseases-2009-2010

25 http://www.orpha.net

26 http://www.fda.gov/RegulatoryInformation/Legislation/FederalFoodDrugandCosmeticActFDCAct/ SignificantAmendmentstotheFDCAct/OrphanDrugAct/default.htm

27 http://www.rarediseases.org

28 http://www.rareconnect.org/

29 http://www.patientsacademy.eu

30 http://ec.europa.eu/health/rare_diseases/docs/ebs_361_en.pdf

To this end, EURORDIS was involved in advocating for the EU Regulations on Orphan Medicinal Products (EC) No. 141/2000 (2000) (Nr. 3), Medicinal Products for Paediatric Use (EC) No. 1901/2006 (2006) (Nr. 4) and Advanced Therapy Medicinal Products (EC) No. 1394/2007 (2007) (Nr. 5) and contributed to the Commission Communication (Nr. 6) and Council Recommendation on an action in the field of rare disease (Nr. 7). As the umbrella organisation for rare diseases in Europe, EURORDIS represents patients on committees such as the European Union Committee of Experts on Rare Diseases (Nr. 8) (EUCERD - formerly the Rare Disease Task Force), European Medicines Agency (Nr. 9) (EMA) scientific committees and working parties and the International Rare Disease Research Consortium (Nr. 10) (IRDiRC).

As the majority of rare diseases are of genetic origin, it is essential to understand the underlying mechanisms and to translate this research into effective therapies. EURORDIS advocated for emphasis on rare diseases in the health theme of the Seventh EU Framework Pro- gramme for Research and Technological Development (FP7) 2007-2011 (Nr. 11). In the reflection paper entitled 'Patients' Priorities and Needs for Rare Disease Research 2014-2020' (Nr. 12), EURORDIS urges public decisionmakers to take a stance in advancing rare disease research on behalf of patients affected by rare diseases in Europe. In the context of the 8th EU Research Framework Programme 2014-2020 (Horizon 2020) (Nr. 13), amendments are currently being reviewed that specifically mention rare diseases. Further, European governments are engaged to adopt National Plans or Strategies on Rare Diseases (Nr. 14) prior to 2013 where research into rare diseases is one of the priorities.

Concurrently, patients' representatives have become increasingly empowered [Ayme et al., 2008] in all aspects of their disease, i.e. gathering knowledge, supporting fundamental research financially and non-financially, collaborating in clinical research, involvement in regulatory aspects, and pricing and reimbursement decisions in addition to being those best placed in understanding 
what it means to live with the illness either as a patient or parent/carer. In this paper, we describe the European rare disease patients' community, actions and achievements, and next steps.

\section{Involvement of Rare Disease Patients' Associations in Research}

Empowering patients in research means recognising that patients can act as full and equal partners, developers or funders of fundamental and clinical research, in rare diseases. They should not be considered only as subjects in clinical trials. Patients' organisations recognise the role they can play in funding research, but clearly state that they do not want to replace public investment in research (Nr. 15).

Between October and November in 2009, EURORDIS conducted a survey in collaboration with the Centre de Sociologie de l'Innovation (Ecole des Mines, Paris, France) to determine in what ways and to what extent patients' organisations support research. The survey was designed to discover which research areas patients considered to be priorities (Nrs. 15, 16).

A total of 772 rare disease patient organisations received an invitation to fill out the online questionnaire, which was available in 6 languages (English, French, German, Italian, Spanish and Hungarian). Valid responses were received from 309 EURORDIS members and nonmembers ( $40 \%$ response rate); estimated to represent approximately 110 rare diseases and 1.3 million patients in 29 European countries. The survey responses, countries and disease types surveyed are represented in tables 2 and 3 .

Of the 309 patient organisations that responded to the survey, $37 \%$ had funded research in the last 5 years. The ability to fund research is clearly linked to their total budget with the majority of organisations supporting research with their own budget but in some cases also needing to organisefundraising activities to complement their pledged financial support. We found a correlation between the age of the association, their total budget and their choice or ability to fund research. Clearly, the more established an association is and the higher the annual budget, the more likely they are to be aware of the importance of research in their area and to be in a position to fund it. To this end, $56 \%$ of the patients' organisations surveyed had integrated scientific boards within their governance structures.

When evaluating the types of financial support provided, it was observed that $77 \%$ fund the initiation and financing of a specific research project, $75 \%$ co-fund the
Table 2. Distribution of responses according to country surveyed

\begin{tabular}{lc}
\hline Country & Number of responses \\
\hline Belgium & 17 \\
Denmark & 9 \\
Finland & 6 \\
France & 49 \\
Germany & 39 \\
Hungary & 16 \\
Ireland & 6 \\
Italy & 43 \\
Netherlands & 16 \\
Romania & 7 \\
Spain & 26 \\
Sweden & 11 \\
Switzerland & 6 \\
United Kingdom & 37 \\
\hline
\end{tabular}

Table 3. Distribution of responses according to disease types surveyed

\begin{tabular}{ll}
\hline Disease types & Number represented \\
\hline Cardiology & 14 \\
Dermatology & 38 \\
Haematology & 10 \\
Metabolism & 13 \\
Multisystem disorders & 38 \\
Musculoskeletal diseases & 22 \\
National alliances & 15 \\
Neurological & 49 \\
Neuromuscular diseases & 27 \\
Oncology & 12 \\
Ophthalmology & 12 \\
Other rare diseases & 59 \\
\hline
\end{tabular}

operating budget of a specific research project, while 54 and $47 \%$ fund the acquisition of research equipment or a fellowship for a young researcher, respectively. Not surprisingly, the priorities are $81 \%$ for basic research, $57 \%$ therapeutics, $56 \%$ diagnosis, and $54 \%$ epidemiology or natural history of the disease. Most patients' organisations do not consider funding research infrastructure as their priority or responsibility.

Importantly, non-financial support is also provided in the form of creating links between patients, researchers and physicians (76\%), identification of patients to participate in clinical trials $(57 \%)$, providing information and counselling for clinical trial participants (49\%), assisting 
in the design of research projects (48\%), and clinical trials (45\%) by highlighting patients' needs and expectations. To a lesser extent, patients' organisations are involved in promoting the collection of biological samples (28\%).

The main results of the survey showed that patients' organisations express a high interest and commitment for research despite great differences in terms of number of members and budget. Patients' organisations show a strong will to collaborate with researchers, not only by triggering encounters between clinicians, researchers and patients, but also by giving them logistical and financial support.

Some of the hurdles that hinder the progress of research in their area, as considered by patients, include relatively few clinicians (68\%) and researchers (67\%) working in their disease area. A lack of coordination between the various specialists involved (52\%). Equally (52\%), difficulties encountered in identifying patients have been acknowledged. Other obstacles as voiced by patients' organisations surveyed include lack of knowledge on the particular disease, no diagnostic tools or animal model and incorrect research focus.

It is increasingly clear that it is crucial to involve patients and patients' organisations in all, particularly early, stages of research (both fundamental and clinical). Patient organisations have played key roles in funding research and in developing medicinal products. One of the most successful examples is the Association Française contre les Myopathies (AFM) (Nr. 17), which gives on average 60 million Euros to research every year. Excluding the AFM, patient organisations in Europe contributed a total minimum of 13 million Euros to research in 2010.

Genethon (Nr. 18) was founded in 1990 by the AFM [and the Centre Centre d'Etude du Polymorphisme Humain $(\mathrm{CEPH})$ ] and has developed products that have obtained an orphan designation. Other examples of successful investment in rare disease research at the regulatory level include the charity Fondazione Telethon (Nr. 19) in Italy, and in a various instances, parent groups have invested in development or have created small biotechs (Nr. 20) and obtained an orphan drug designation for their product.

\section{Support and Funding for Research and Development at National and European Levels}

\section{National Plans for Rare Diseases - EUROPLAN}

The EUROPLAN project (Nr. 14) complements the Council Recommendation that invited Member States to establish and implement plans or strategies to ensure pro- visions aimed at fostering research in the field of rare diseases in particular translational research. Consequently, national conferences have been organised in 15 European countries in the context of the EUROPLAN project with 20-25 more planned before the looming deadline of 2013. The conferences included a multitude of national stakeholders in the field of rare diseases and assessed the transferability of the EU policy documents in 6 main areas, including research on rare diseases. Particular emphasis was placed on the role of qualified patients as fully fledged research partners; the importance of centres of expertise in closing the gap between research and care; the necessity of quality patient registries to develop rare disease research; and the absolute need for multi-centred national and international investigations, in particular for clinical trials.

\section{Support for Research at the European Level}

Framework Programme 7

In the lead up to the launch of the Framework Programme 7 (FP7), the need to invest in rare disease research and to identify the requirements of the rare disease scientific community was addressed in a European Commission workshop in April 2005 entitled 'Towards FP7.'

Several important conferences were organised in 2007 around the launch of the FP7 call; in May, EURORDIS organised a European workshop on 'Gaining Access to Rare Disease Research Resources' in Paris; in June, the European Commission held a workshop on 'Rare Diseases and Research', and in September, the European Conference entitled 'Rare Diseases Research: Building on Success' took place in Brussels, organised under the aegis of the European Commission, DG Research.

The specific line for rare diseases in the FP7 call emphasised the inclusion of patients as contributors, evaluators and advisors, in advisory groups and also as participants/beneficiaries by the European Commission.

The FP7 call and the subsequent key documents, the Commission Communication on Rare Diseases and the Council Recommendations, represent milestones in rare disease policy. These emphasise a need for a rare disease research policy that is both comprehensive (from basic to clinical research) and integrated (EU and national levels) and demonstrate recognition of the importance of investing in this area.

A very inspiring example of motivation and tenacity is that of the AKU Society (Nr. 21) for alkaptonuria who has teamed up with academics (University of Liverpool) and a pharmaceutical industry sponsor and successfully applied for and secured an FP7 grant to investigate a medicinal product for this disease. 
Support for Research at the International Level

Patient involvement in research and development extends beyond the European level to international networks and initiatives to improve the coordination of research.

\section{ECRIN - European Clinical Research}

Infrastructures Network

Supporting national or international networks organising clinical trials is essential to address the limited number of patients and the scarcity of expertise as well as to promote clinical and preclinical testing in cooperation with the pharmaceutical industry.

The ECRIN (Nr. 22) is a European network dedicated to improving the health of patients and citizens across the world through clinical research. ECRIN supports multinational clinical trials in Europe by providing services and instruments to facilitate clinical research to international teams. By facilitating clinical research across Europe, ECRIN contributes to the achievement of the 'European Research Area' and the 'society of knowledge' and adds to European competitiveness.

Patients' involvement in the ECRIN project include representation in ethics committees, design of outcome measures, scientific evaluation (in ECRIN IA), and members of scientific and ECRIN advisory boards as well as involvement in discussions at global level on acceptability of the risk and training.

\section{ERA-NET for Research Programmes on Rare}

Diseases

E-RARE is a European Research Area ((ERA)-NET) (Nr.23) funded project that aims to coordinate national or regional research programmes on rare diseases and develop joint and strategic activities to harmonise and to implement transnational research funding actions. The ERA-NET scheme aims to increase the cooperation and coordination of research activities performed at national or regional levels in EU Member States and Associated States through networking of research activities and mutual opening of national and regional research programmes. The idea is to improve the coherence and coordination across Europe of such research programmes. The scheme will also enable national systems to take on tasks collectively which they would not have been able to tackle independently.

E-RARE performed a survey on the funding of rare disease research by public partners in their own countries (Nr. 24). This survey emphasised the importance of increasing funds for rare disease research, supporting in particular proof of concept studies and gaps in transla-

Patients' Involvement in Rare Disease Research tional research; promoting EU funded research networks; facilitating mobility for clinicians; and promoting rare diseases as model for common diseases in research. Patients' groups such as EURORDIS have participated as observers in the E-RARE project.

In parallel, Orphanet (Nr. 25), the portal for rare diseases and orphan drugs, performed a survey and found that while rare disease research is growing (approximately 5,000 ongoing research projects covering 2,000 different rare diseases, 650 clinical trials for more than 300 diseases), research activities such as research project, registries, clinical trials, and orphan drug development are strikingly focused on relatively few rare diseases (e.g. cystic fibrosis or Duchenne muscular dystrophy). For the majority of rare diseases affecting fewer than $1 / 10,000$, therapeutic research is absent or very limited. It emerged from the survey that the 3 main determinants for reaching a significant research activity level in a given rare disease are the (i) existence of patient organisations, (ii) patient registries and (iii) a European network (of centres of expertise or of research) where all actors are already involved.

\section{International Rare Disease Research Consortium (IRDiRC)}

This initiative is an international collaboration in rare diseases research involving the European Commission, Health Directorate, DG Research and Innovation, and the US National Institutes of Health. Two preparatory workshops were held in October 2010 and April 2011 in Reykjavik, Iceland, and Washington, DC. IRDiRC (Nr. 10) was officially launched in April 2011. The aim is to team up researchers and funding agencies in order to achieve 2 main objectives by the year 2020 , namely to deliver 200 new therapies for rare diseases and diagnostic tools for most rare diseases. Patients organisations have been included in the Executive Committee as well as in the Therapies, Diagnostic and Interdisciplinary scientific committees.

\section{Patients' Organisations Involvement in the Regulatory Processes}

Initiatives such as the Orphan Drug Act (Nr. 26) in the US (1983) and the EU Regulation on Orphan Medicinal Products (1999) (Nr. 3) demonstrated an understanding that incentives were needed to support and encourage industry to invest in developing treatments.

Europe is in a unique situation for the inclusion of the patient voice as decision-makers in the regulatory processes. In 2000, the Committee for Orphan Medicinal 


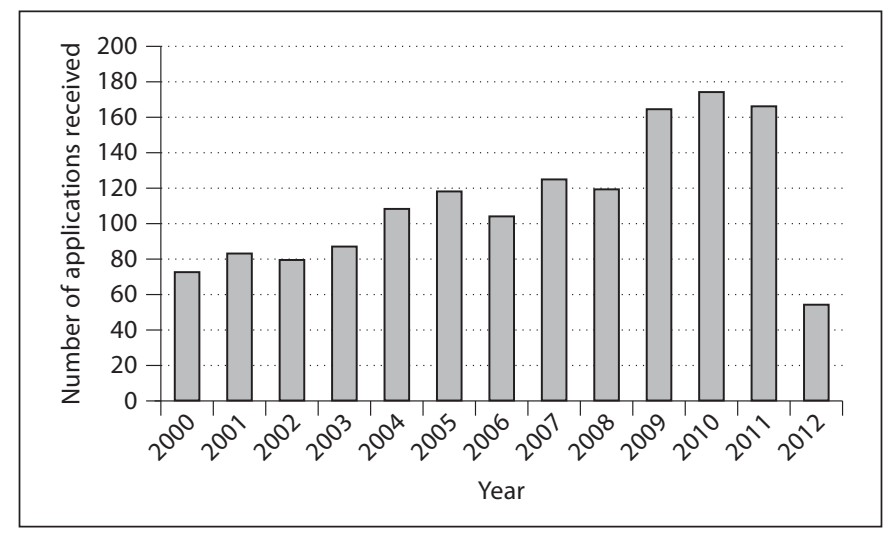

Fig. 1. The number of applications submitted to the Committee for Orphan Medicinal Products at the European Medicines Agency for evaluation for orphan drug designation since 2000.

Products (COMP) was formed at the European Medicines Agency (EMA), and the European authorities had the foresight to include patients' representatives as permanent and full members with equal voting rights (Nr. 3). Three patients' representatives sit on this committee, and the position of vice-chair of the COMP has always been held by a patients' representative.

The question why we need an orphan regulation has been raised several times and most recently in 2010 at the time of celebration its 10 th year of implementation. Has it been successful? Has it achieved its objectives? The purpose of the (EC) No. 141/2000 was to encourage and stimulate research and development in the field of rare disease by reducing regulatory fees (and in some cases waiving them completely) and modifying market conditions by providing exclusivity for 10 years. The steadily increasing number of orphan drug applications (fig. 1) and the resulting marketed orphan drugs is evidence of its success. There is no doubt of the need to address the imbalance between designations and marketing authorisations; however, the orphan drug regulation has certainly achieved the purpose of encouraging research in this area [Committee for Orphan Medicinal Products, 2011].

Since the creation of the COMP, a working party and 2 more scientific committees have been created; the Patients' and Consumers' Working Party (PCWP) in 2004, the Paediatric Committee (PDCO) in 2008 and the Committee for Advanced Therapies (CAT) in 2009, and the Pharmacovigilance Risk Assessment Committee (PRAC) due to be formed in 2012, all of which include patients' representatives. These patients' advocates in scientific committees have the same role as the other members with equal voting in the decisions made.

In addition to their regulatory roles of evaluating dossiers submitted for compliance with the orphan designation criteria (COMP), approval of a Paediatric Investigation Plan, (PDCO) or classification of an advanced therapy medicinal product (CAT), activities of patients' representatives in the framework of therapeutic development include (i) promoting drug development, (ii) ensuring clear information to patients and (iii) attempting to achieve equal access to treatments both at European and national levels.

\section{Other Initiatives}

As observed for several years, in addition to research activities described, patients' organisations are making full use of the internet to research and disseminate information. This medium can represent an important part of the life of a patient where views can be expressed and shared and information from a community can be accessed.

\section{Online Communities}

Social media provide a great opportunity to build awareness of the disease and highlight the patient's perspective. However, the internet comes with a great deal of responsibility, but no real content monitoring. Information from patients who are recording responses to treatments, effects of different treatments etc. is being shared via social media [Polich, 2012]; however, while this information could serve as priceless to public and private researchers, the safety of the patient must always remain a key consideration.

EURORDIS and its North American partner, the National Organization for Rare Disorders (NORD) (Nr. 27), initiated the RareConnect project (Nr. 28), which are disease-specific patients' communities that have been created by dedicated patient organisations. These networks have moderators who represent people with real experience with their disease and who monitor content uploaded onto the site.

\section{Training}

There is recognition of the fact that in order to involve patients' representatives in activities such as those described, there is a genuine need for education and training in the relevant areas. Many training initiatives launched by patients' organisations exist, such as European AIDS Treatment Group (EATG), Thalassaemia International Federation (TIF), the European Federation of 
Neurological Associations (EFNA) and the European Patients' Forum (EPF). EURORDIS also has launched a training initiative called the EURORDIS Summer School, a training course providing an overview of clinical trials, drug development and regulatory procedures which has been identified as an essential tool to address these needs. The objective of this training is to support patients' advocates by providing them with the tools to put together a complete picture of drug development from clinical trials to market authorisation. To date, more than 150 participants (31 different countries and more than 65 different diseases) have been trained and have gone on to become involved in various advocacy activities, both at their national level and at the European level.

As a part of this success and in the context of ECRIN, non rare disease patients are also being trained in the Summer School from 2012, and a new IMI-funded project, the European Patients' Academy on Therapeutic Innovation (EUPATI) (Nr. 29), was launched this year to increase capacities and capabilities of patients and patients' organisations to be effective advocates and advisors in medicines research.

\section{Conclusions}

Common themes can be identified. There is a need for Europe as a whole, as well as individual member states, to recognise the need and the importance of rare disease research, which frequently leads to more understanding of common diseases and to invest in it. It is imperative to maximise scarce resources (either financial or rare disease patients) and to coordinate research efforts. Sharing of data and samples is essential to support research that is currently being hampered by the absence of an exhaustive rare disease classification, standard terms of reference and common ontologies, as well as harmonised regulatory requirements (Nr. 10).

Public and private researchers should initiate collaboration with patients and patients' organisations at early stages of development. Patients are the best placed to understand their disease, the clinical differences that a treatment can make and also the contributions that can assist fundamental research such as funding or access to biological samples from other patients. This is particularly true for patients with rare diseases.

Since the Orphan Drug Regulation came into force 12 years ago, Europe has seen an evolution in the attitudes towards patients and from patients towards themselves. The rare disease community in particular is becoming empowered through various actions at local and at the European level; this has arisen from a need to address a definite lack of understanding of this unique patient group. The Eurobarometer (Nr. 30) has shown that a certain awareness exists regarding rare diseases and their particular concerns and requirements. Initiatives such as Rare Disease Day will hopefully only increase this awareness. The impact of the above-mentioned initiatives will inevitably be the systematic inclusion of rare diseases in funding projects and of patients as equal partners in the context of research on rare diseases.

With respect to its future involvement in research, EURORDIS envisages the continuation of current activities in addition to the creation of a scientific advisory board as well as developing partnerships with learned societies. The next important and neglected area of research that needs to be addressed is research into social aspects of living with a rare disease, which need to be performed in a systematic scientific manner in collaboration with policy research academic teams whose results could contribute to the development of innovative policies and services.

\section{Acknowledgements}

The authors would like to acknowledge the work of Valentina Bottarelli, Monica Ensini and Fabrizia Bignami in the context of the reflection paper that was extensively used for this article. Further, Monica Ensini and Nancy Hamilton are kindly acknowledged for critical reading of the manuscript.
References

\footnotetext{
Ayme S, Kole A, Groft S: Empowerment of pa- Kaye J, Curren L, Anderson N, Edwards K, Fultients: lessons from the rare disease community. Lancet 371:2048-2051 (2008).

-Committee for Orphan Medicinal Products and the European Medicines, Westermark K, Holm BB, Söderholm M, Llinares-Garcia J, Rivière $\mathrm{F}$, et al: European regulation on orlerton SM, et al: From patients to partners: participant-centric initiatives in biomedical research. Nat Rev Genet 13:371-376 (2012).

Polich GR: Rare disease patient groups as clinical researchers. Drug Discov Today 17:167172 (2012).
} phan medicinal products: 10 years of experience and perspectives. Nat Rev Drug Discov 10:341-349 (2011). 